\title{
Negotiated social space: a relook at partnership in contemporary health care
}

\author{
Julianne Cheek
}

University of South Australia, Adelaide, Australia

\begin{abstract}
Partnership figures prominently in the rhetoric of contemporary health care. The notion of an 'active', 'informed' patient in partnership with health care providers has permeated practice and policy globally. Consequently, understandings of partnership have colonized the social space that exists between health care providers and health care recipients. Drawing on Foucault's notion of discourse, this paper explores partnership as a discursive event and interrogates the way understandings about partnership construct how partnership is enacted, including the subject positions of health care professional and patient, which in turn construct understandings about partnership. The paper argues that partnership is more than simply participating in health care. It involves questioning who is offering whom what, and how. The discussion aims to trouble and unsettle taken for granted assumptions about partnership to allow for the possibility that partners can position themselves in the social space that is the site of the partnership in a way that enables the type of professional relationship and outcomes to be negotiated by both partners.
\end{abstract}

Key words: discourse; Foucault; health care policy; health care practice; partnership; power

\section{Introduction}

Twenty years ago Armstrong (1983: 25) argued that there had been a shift in modern medical discourse from one with a focus on biological pathology, to one that increasingly focused interest on the 'social space between doctor and patient'. The past two decades have seen a continued rise in interest in the nature of the relationship between health care providers and recipients of that health care. Concomitant with this, contents pages of both journals and conference proceedings conveying work in the area of health care provision reveal an increasing interest in, and presence of, papers extolling the virtues of the participation of patients in their health care. Such papers often draw on what have now become familiar themes, namely the need for individuals to be able to take more

Address for correspondence: Julianne Cheek, Director, Socially Sustainable Health Research Centre, University of South Australia, City East Campus, North Terrace, Adelaide, South Australia, 500. E-mail: Julianne.Cheek@unisa.edu.an control of their health and be active rather than passive recipients of health services. Often the participation of patients in their health care is presented as a form of partnership between recipients and providers of health care services.

I am using the term 'patient' throughout this paper to refer to the individual receiving health care. I am aware of debates around the use of the term, and the arguments for using 'consumer'/ 'client' or 'person' instead. However, mine is an expedient choice in that most authors whose work I refer to in this paper use the term 'patient' and it is simply too cumbersome to do otherwise. Further, as this paper argues, simply changing the word 'patient' to 'consumer' does not in itself ensure a more equal or active partnership.

Gallant et al. (2002) have done an extensive analysis of the concept of partnership and trace the antecedents to, and emergence of, the notion of partnership and its ascendancy into contemporary health care rhetoric and writing. They note that literature from a variety of disciplines reveals 'an implied consensus that partnership is an interper- 
sonal relationship between two or more people who work together towards a mutually defined purpose' (2002: 153). Their observation that the writing that is done about partnership often reveals an implied consensus about what partnership is raises the possibility that understandings of partnership and what it involves may vary from person to person and situation to situation. It also opens the possibility that partnership is a taken for granted concept both in terms of its meaning, its implementation and its effects. Gallant et al. (2002: 156) go on to highlight tensions both within the term 'partnership' itself, and in its implementation, advocating among other things research that could help to determine whether partnership is truly an egalitarian concept or an elitist idea'. They conclude, drawing on Morse et al.'s (1996: 387) notion of a mature concept as one where there is 'consensus and consistency with its use among theoreticians, researchers and practitioners', that partnership could be considered an 'immature concept that has relevance and potential for further inquiry as the movement towards egalitarian models of interaction grows in the health care discourse and practice' (Gallant et al., 2002: 156).

In keeping with Gallant et al.'s (2002) assertion, this paper is offered as a contribution to further enquiry exploring aspects of partnership as it has been spoken and talked about in some areas of contemporary health care. Such an exploration is of particular relevance to the primary health care area that has long recognized the importance and centrality of the patient, and the relationship between the patient and health care professional, in health care provision and promotion. Indeed it has been this very emphasis that has been promulgated as a distinctive feature of primary health care (see, for example, Courtney, 1995; Courtney et al., 1996). However, before going further, some caveats need to be acknowledged. The discussion that follows is in many ways preliminary and far ranging. It is limited in that it raises many issues without being able to fully explore each of them in a paper of this scope. Thus rather than providing an exhaustive analysis of partnership per se (others have written more extensively about this; see, for example, Cahill, 1996; Gallant et al., 2002), the aim is to unsettle some taken for granted understandings that may have congealed in understandings about partnership and the way that partnership is, and can be, enacted in the health care arena. In so doing, it is to take a relook at aspects of the social space between health care provider and health care recipient that constitutes the sphere in which partnership is premised, negotiated and enacted. The working definition of partnership that is offered in order to provide parameters for the discussion to follow draws on Gallant et al. (2002: 149) who note that:

The attributes of partnership include structural and process phenomena. The structure of partnership includes the phases of the relationship, focus and aims of each phase, and roles and responsibilities of the partners. The process of partnership embodies power sharing and negotiation. The main consequence of partnership is client empowerment, which is understood to be the improved ability of the client to act on his/her own behalf.

\section{Partnership as an emerging groundswell in contemporary health care policy}

The idea of partnership between health care professionals and health care recipients has emerged as a very strong thrust in policies pertaining to contemporary heath care. For example, the development of the 'Expert Patient' initiative in the United Kingdom, focusing on the care of those with chronic illnesses, is an example of a policy developed with partnership in mind. The Expert Patient initiative is a response to a belief that in the past strategies failed to 'recognize how people can play a positive part in building healthy lives for themselves and in contributing to the health of other members of society' (Department of Health, 1999: 3.2). Wilson (2001: 134) provides the following summary of the approach underpinning the Expert Patient initiative: 'The State will empower the Expert Patient and provide the appropriate resources to meet the needs of those with chronic illnesses, whilst simultaneously encouraging the Expert Patient to self-care and manage their condition'.

Drawing on similar rhetoric to that of the United Kingdom Expert Patient initiative, the then Australian Federal Health Minister announced a $\$ 14.4$ million Chronic Disease Self-Management 
program in the 1999-2000 Australian Federal budget, stating that 'effective self-management is based on partnerships between the person with a chronic disease, their families and health professionals' (Wooldridge, 2000: 2). The Minister went on to say that '[T]his national initiative encourages people to play an active role ... as well as conforming to the right kind of treatment' (Wooldridge, 2000: 2), with specific reference to primary health care. Some 3 years earlier, in 1996, the American Nursing Association (ANA), when outlining the goals of primary care to address patient needs and concomitant health care provider responsibilities, had identified key components of such primary care to be accessibility, prevention and general wellness care of individuals and families. The ANA noted that 'clients and providers share responsibility for health outcomes' (Bischoff and Kelley, 1999: 42). Around the same time, the North American-based Institute of Medicine (IOM) declared primary care to be integrated, accountable and accessible health care, with providers being accountable by 'developing sustained partnerships with patients' (cited in Bischoff and Kelley, 1999: 42). Policies and programs such as these (and they have been chosen simply as exemplars) form part of an emerging global groundswell in the rhetoric pertaining to health care delivery and policy - a groundswell that has seen ideas of partnership become almost taken for granted in much writing about contemporary health care. It is seemingly widely accepted that partnership is an admirable initiative moving us on from lopsided power arrangements between health care providers and recipients of that health care. Indeed, the 1997 UK report, Medicines partnership: from compliance to concordance, an initiative which grew out of a partnership between the Royal Pharmaceutical Society of Great Britain and the drug company Merck Sharp \& Dohme, asserts that: 'So complex are the challenges of modern medical treatment that teamwork is essential: the closest partnership is required between all concerned. Crucial to the achievement of such therapeutic partnerships is the inclusion of the patient as partner' (Marinker, 1997: 3).

Thus in much of the contemporary writing and policy about health care delivery there is an underlying sense that the tide has turned in favour of better, collaborative health care relationships premised on a sense of partnership. Indeed, notions of partnership have colonized the social space between health care provider and health care recipient. They have been used to shape that space, even define that space. The understandings that emerge therefore constitute health care providers and health care recipients in new and different ways. As Silverman and Bloor (1990: 4) pointed out in their incisive analysis of patient-centred medicine, a strategy that the contemporary trend towards partnership in health care has drawn on, such strategies also involve the 'strategic constitution or construction of patients by practitioners' (emphasis in the original) where patients are constituted 'as particular kinds of subjects with particular kinds of attributes by the operation of specific institutional and discursive practices' (1990: 7). In other words, understandings of patient and health care professional themselves are constituted in new and/or different ways by the emergence of understandings of what partnership in health care provision might mean. In turn, these constitutions impact on understandings of what partnership itself might mean and be.

\section{Partnership as a discursive event}

Foucault's (1980) notion of discourse can assist the discussion here. Foucault, a French social theorist, challenged the notion of knowledge as objective and value free. He argued instead that knowledge is intimately connected to power and explored what he termed the 'knowledge/power' nexus through the concept of discourse. In Foucauldian analytical frames, 'discourse' can be understood to refer to ways of thinking and speaking about aspects of reality: 'a discourse provides a set of possible statements about a given area, and organizes and gives structure to the manner in which a particular topic, object, process is to be talked about' (Kress, 1985, p. 7). This includes the way that aspects of health care are thought about and represented. Foucault (1980) argues that practices, for example partnerships in health care, are discursively framed - that is, they are produced by the dynamic relationship between power/ knowledge that gives exponents of particular discourses the ability to speak with authority and conversely relegate other ways of viewing and understanding aspects of reality to the margins.

For example, Foucault (1975) explored how the 
idea of the clinic as central to health care practice was able to emerge in contemporary health care. In his analysis, 'the emergence of the clinic itself was only possible because of the emergence of certain types of discursive frames and associated knowledges. The clinic, in turn, operated to further produce certain types of knowledge whilst excluding others' (Cheek, 2000: 26).

Thus Long (1992: 119-20), drawing on Foucauldian frames, asserts: 'the clinic is more than a place where medicine is practised, it is also a discursive practice, a language of health and disease'. In the same way, to paraphrase Long, it can be argued that partnership is more than a way in which health care is practised or delivered; it is also a discursive practice, a language of health and health care delivery. Understandings of partnership are both constructed by, and in turn construct, understandings of health, health care and other associated knowledge. So it might be asked whether understandings of partnership, such as those implicit within the Expert Patient initiative and other descriptions of aspects of the provision of contemporary health care, create certain subject positions and subjectivities for both the recipients and providers of health care.

In such an analysis, the discursive practices that both construct, and in turn are constructed by, the discursive event termed 'partnership' can be viewed as strategies of power (Silverman and Bloor, 1990). Foucault asserts that these practices can become so deeply ingrained in us that we no longer perceive them as 'an effect of a power that constrains us; on the contrary it seems to us that truth, lodged in our most secret nature, "demands" only to surface' (Foucault, 1981: 60). This may well be the case with respect to the surfacing of the central, beneficent, and almost at times 'common sense' status afforded the concept of partnership in contemporary health care rhetoric.

The discussion now turns to briefly consider aspects of partnership in contemporary health care provision in order to further explore and develop the idea of partnership as being discursively constituted and both a strategy, and effect, of relations of power.

\section{Partnership as both strategy and effect of relations of power}

Paterson (2001) has written about what she terms the myth of empowerment in chronic illness. She argues that the 'rhetoric of empowerment does not always match what happens in reality, noting that the "practitioner as expert" model of health care may be so deeply rooted that they [practitioners] proffer patient participation largely as an extension of their power base, rather than as a collaborative venture' (2001: 575). In so arguing, Paterson brings into focus and questions the notion of partnership by asking whether the partnership and any consequent empowerment (assumed or otherwise) of an active (assumed or otherwise) participant in their health care provision occurs only within certain boundaries determined by recourse to the dominance of the discourses on which the professional expertise of the health professional concerned is premised. As Silverman and Bloor (1990: 5) note, 'the therapeutic relationship is always a power relationship'. The subject position of the patient in the partnership is largely the effect of the power of the health care professional to determine the parameters of that partnership. Thus in much of the writing about partnerships in health care it is the patient who is to be empowered by the health professional not the health professional by the patient, just as it is the Expert Patient (Wilson, 2001) who is to be empowered by the State - not the State by the Expert Patient.

Viewed in this way, the patient is positioned as part of a partnership, the parameters of which are often determined by others, rather than being an active participant in determining the way that the partnership itself should occur. As Hindess (1996: 105) points out, 'successful government of others is often thought to depend on the ability of those others to govern themselves, and it must therefore aim to secure the conditions under which they are enabled to do so'. Policy and rhetoric that enshrines the notion of partnership and collaboration between health professional and patient also enshrines understandings of how that partnership and collaboration should occur, and what the outcome should be. Thus Wilson (2001: 141) comments that although the Expert Patient initiative 'does focus on the rights and responsibilities of those with chronic illness, there is no corresponding strategy to challenge professionals' assumptions and actions towards those with chronic illness'. Gillibrand and Flynn (2001: 507) concur with these sentiments noting, when writing from a different context and perspective, that further enquiry is needed into "how health professionals 
appear to take ownership or responsibility for the person's condition'. Indeed Gwyn and Elwyn (1999: 437) suggest that at times so-called shared decision making might be more accurately 'described as an informed decision engineered according to doctor [or health professional] preference'. Thus participation in health care by patients and/or health professionals is not necessarily synonymous with partnership, which, in turn, is not necessarily synonymous with sharing power. The assumption that increased participation results in increased power or a better partnership is simplistic (cf. Allen, 2000). It is possible to participate in health care, but not be in partnership. Equally it is possible to choose not to participate and be in partnership.

Communication is at the core of any effective partnership. Kettunen et al. (2001: 400), writing from a nursing perspective and drawing on research about taciturn patients in hospital health counselling situations, comment that in most of the literature 'patients' contribution to the content and organization of nurse-patient communication has largely been ignored'. It is the health professional, in this instance the nurse, who is able to take control of the situation. Kettunen et al. (2001: 414) note that the nurse does so "by speaking more strategically than patients do'. Similarly, elsewhere I (Cheek, 1997) have argued that there is a delicate (or sometimes not so delicate) negotiation that occurs in the positioning of, and subsequent communication between, health care providers and their clients. Communication itself, rather than a neutral conveyor of information, can actually work to create and sustain dominant understandings in health care-based partnerships.

Viewed this way communication is a strategy of power, the outworking of a network of power relations that shape and enmesh the discursive event termed 'partnership'. For example, a study by Kingfisher and Millard (1998) found that clinic staff often ignored or discounted women's questions if they were not considered to arise from a biomedical understanding of disease or treatment. The women were able to speak and be heard, but only if they spoke from a particular viewpoint drawing on certain understandings of health and health care. Put another way, the women were able to speak and be heard - but only if they spoke from a position created for them by the understandings on which the expertise of the clinic staff was premised. The parameters of any partnership were clearly established by the discourses emanating from, and legitimized by, the knowledge of the health professional. This enables anything not fitting within these understandings to be relegated to the margins or worked on to 'comply' or 'conform'. Thus it is not surprising that the former Australian Health Minister, when announcing the Chronic Disease Self-Management Program alluded to in an earlier section of this paper, asserted that it "encourages people to play an active role ... as well as conforming to the right kind of treatment' (Wooldridge, 2000: 2; my emphasis). In seeking to encourage people to conform to the right kind of treatment the self is encouraged to act upon the self. Any subsequent partnership becomes the effect of power relations; the 'partnership' that is enacted as a consequence is 'an interrelationship between active persons in such a way that one agent aims to control the conduct of another' (Gilbert, 2001: 203).

\section{Partnership: dramatis personae in whose script?}

Smith's (1999) analysis of the way the form and function of research reports actually disempower and marginalize participants, even those reports that overtly intend to include participants as partners in the research process, is useful to bring into the discussion at this point. Smith (1999) argues that texts that purport to convey the experiences, understandings and words of participants are constrained by the form of the research report itself. What emerges is fragmented, incomplete and framed to suit the purposes and needs of the researcher as creator and controller of the parameters of the text. Thus she writes of a report on soccer violence where, at the start of the book, the authors describe the young men studied as the 'dramatis personae':

The metaphor expresses exactly the sociological relation created in the text. Respondents have the appearance of free agents. They have the appearance of speaking with their own voices. But, in fact, the sociologists' script prescribes how they appear and 
what they say. The sociologists speak through their dramatis personae.

[Smith, 1999: 67].

Smith's play analogy challenges us to consider whether at times patients in supposedly empowering partnerships pertaining to their health care are in fact the dramatis personae in somebody else's predetermined and written script. Is the partnership between health care professional and patient the product of, and in turn producer of, understandings about expertise, authority, legitimate knowledge and the power concomitant with that knowledge to exclude and marginalize ways of thinking and acting?

To illustrate this point further, the focus of the discussion turns to an article by Laine and Davidoff (1996) that, whilst it is no doubt well intentioned in advocating a shift to patient-centred care, may in fact mitigate against that very goal. Laine and Davidoff argue that the shift from providerfocused care to patient-centred care enables patients to participate in medical decisions. They state: '[A]s medicine becomes more patient centered, participation begins with the patient helping to decide what the physician will order, and the emphasis shifts from compliance to participation' (1996: 153). Laine and Davidoff (1996: 154-55) conclude: '[P]hysicians are recentering their point of view by explicitly incorporating patients' perspectives into medical care ... In our view, incorporating patients' perspectives into the fabric of medicine from the bedside through quality assessment can only enhance the state of medical science'.

In such a scenario patients are able to be in partnership but only within the medical frame. The discursive understandings that underpin medical practice, such as claims to expertise and the right to prescribe courses of action, are not challenged they are part of the regimes of truth alluded to by Foucault. As Foucault (1980: 131) asserts:

Each society has its régime of truth, its 'general politics' of truth: this is, the types of discourse which it accepts and makes function as true; the mechanisms and instances which enable one to distinguish true and false statements [or right and wrong treatments], the means by which each is sanctioned; the techniques and procedures accorded value in the acquisition of truth; the status of those who are charged with saying what counts as true.

It is the physician's point of view that patients' perspectives are being incorporated into; in effect, the patients' views are colonized and inscribed by the dominant discursive frames in operation. Partnership occurs, but only within a position determined for the patient by others. Partnership would be understood differently if it was the physician's perspective that was being incorporated into the patient's point of view.

Similarly, in her study of self-care decision making by people with type 1 diabetes, Paterson (2001: 578) reports that 10 participants 'stated that their experiential knowledge is discounted when practitioners consider only information derived from textbooks as valid, and do not heed data that contradict textbook information'. Here textbook information (like medicine in Laine and Davidoff's (1996) analysis) occupies the main frame. A patients' experience is relevant and taken on board if it fits within the frame. If not, it is relegated to the margins or at worst excluded. There is some play around the margins in terms of incorporating other perspectives and patients' understandings, but it is only ever around the margins and within a predetermined space and locus of control. To dismiss such information out of hand, or to listen only to reject, delegitimize or 'trump' with the full weight of authority premised in health expertise, is to disempower. It is to ensure that if partnership occurs it is only possible according to certain ways of knowing and not others. This is why Frank (2001: 361) suggests that one aim in his writing about suffering is to 'offer professionals an enhanced sense of the different stories people tell; to get them to think less about these stories and more with these stories'. This suggests that simply listening to patients is not enough. Nor is a good communication style such as an approachable manner adequate. While these qualities are important, in themselves they do not necessarily result in partnership; neither does the provision of information that is derived from only one perspective of the health issue and which is not cognisant of other ways of viewing and understanding the issue - including the patient's own experience.

All of this is to challenge the very powerful rhetoric that pervades much contemporary health care practice around notions of an 'empowered' 
consumer acting in equal partnership with a health care provider. Partnership is more than participating in health care. Partnership also involves questioning who is offering whom what, and how. The actual act of offering a role to patients in their health care is not partnership in itself. Instead it can act to sustain and reinforce existing power relations and authoritarian claims in health care provision. By this I mean that if partnership is only offered in terms of the understandings of one of the players in the partnership then it can actually work against the intention of wishing to act in partnership in the first place. In such a partnership, the other player is simply dramatis persona in someone else's script.

\section{Summation - where to from here?}

So where does all this leave us? In a position that discounts partnership as undesirable or unachievable? Not at all. There is no doubt that health professionals believe that they are acting in the best interests of patients when they seek to work with patients in partnership in the provision of health care services. The danger inherent in all of this is that the rhetoric of partnership becomes a new form of orthodoxy, both in terms of the need for partnership, and the subsequent way in which it should occur in practice. Partnership cannot be reduced to a checklist where elements can be ticked off by health professionals from their standpoint. If this is the case then partnership becomes merely a script in which patients are invited to participate but not to write.

It is also important to point out that not all patients always want to be autonomous, or want to have information presented to them in volumes, or want to assume responsibility for the self-management of their conditions. As Lupton (1997) points out, patients may move in and out of the roles of the active partner in, and the passive recipient of, health care. Patients who are forced against their wishes to be in a certain type of partnership are actually disempowered in that once again they are passive recipients of what others have determined is in their best interests.

Likewise it may be the case that partnership is a script in which health professionals themselves are also dramatis personae rather than playwright, particularly as policy attempts to enshrine prin- ciples of partnership in practice. Both health professionals and patients are enmeshed (Bordo, 1993) in a web of power relations. It is not simply a case of the health professional having power and the patient not (Cheek, 1997). Rather, partnership reflects the way that they are positioned in relation to one another, the way the social space between health professional and patient is discursively framed and thereby understood, for

power and powerlessness are in one sense transitory - the result of being positioned in one way or another, of being positioned or positioning oneself in terms of one category or another, in terms of one discourse or another, as one who can and should act/speak/write powerfully, or as one who cannot or should not.

(Davies and Hunt, 1994: 389)

The Medicines Partnership initiative (Marinker, 1997) is a powerful example of how thinking about what partnership is, and might be, can influence the way the social space between patient and health care professional is negotiated and framed. In detailing the evolution of this initiative, the report notes that a clear focus of the working party's initial concern 'was the achievement of more compliant medicine taking' (Marinker, 1997: 11). However, in the course of exploring how to achieve such compliance, the working party noted that to achieve taking medicines to best effect there needed to be 'a fundamental shift in the balance of power in the clinical encounter. This will require the closest attention to and genuine respect for, the validity of the patient's personal constructs and coping strategies' (Marinker, 1997: 12). The working party used the term 'concordance' to encapsulate the type of partnership that could 'optimise health gain from the best use of medicines, compatible with what the patient desires and is capable of achieving' (Marinker, 1997: 12; emphasis in the original).

Concordance involves respect for the beliefs and perspectives of both the health care professional and patient. It does not abandon scientific evidence but neither does it 'lend itself to one-sided negative inversion' (Marinker, 1997: 13). Rather, concordance builds on a negotiated space between the health care professional and patient - a space where there may be the possibility of difference. This puts the emphasis on the partnership, not the 
health care professional or the patient. In such an understanding of partnership the patient cannot be nonconcordant although they may be noncompliant with respect to prescribed regimes of treatment. Rather, it is the consultation or the encounter between health professional and patient that is nonconcordant. This understanding thereby shifts the focus on to the negotiated space between the health care professional and the patient, and how to better use and understand that space. The focus is not on the patient and ways of making the patient compliant. This represents an important conceptual shift in the understanding of partnership and gives main frame to alternative discourses about health care that may have been relegated to the margins by understandings premised on dominant medical and scientific discursive frames such as 'compliance'.

Smith refers to her research as writing the social. She asserts that ' $[\mathrm{W}]$ riting the social profits from the dialogue between what we mean to say and what we discover we have said, and, of course, the work of rewriting to embrace what we find we have said that is beyond or other than our intentions (1999: 9).

This paper has attempted to create such a dialogue designed to unsettle and trouble some of the assumptions about partnership that have become central planks in much contemporary health care rhetoric. The aim of engaging in this dialogue is to assist in ensuring that when we speak of giving health care recipients and health care professionals access to, or involving them in, partnerships in health care provision, we do just that.

\section{Acknowledgements}

Professor Julienne Meyer provided constructive and rigorous critique of an earlier version of this paper. Joh Wurst and Tori Hocking provided editorial and research assistance in the preparation of this paper. An earlier version of this paper was presented at 'The Question of Community Nursing Research', an international symposium of the International Conferences in Community Health Nursing Research, London, September 2001.

\section{References}

Allen, D. 2000: 'I'll tell you what suits me best if you don't mind me saying': 'lay participation' in health care. Nursing Inquiry 7, 182-90.

Armstrong, D. 1983: The fabrication of nurse-patient relationships. Social Science and Medicine 17, 457-60.

Bischoff, W.R. and Kelley S.J. 1999: 21st century house call: the Internet and the World Wide Web. Holistic Nursing Practice 13, 42-50.

Bordo, S. 1993: Unbearable weight: feminism, Western culture, and the body. Berkeley: University of California Press.

Cahill, J. 1996: Patient participation: a concept analysis. Journal of Advanced Nursing 24, 561-71.

Cheek, J. 1997: Negotiating delicately: conversations about health. Health and Social Care in the Community 5, 23-7.

Cheek, J. 2000: Postmodern and poststructural approaches to nursing research. Thousand Oaks, CA: Sage Publications.

Courtney, R. 1995: Community partnership primary care: a new paradigm for primary care. Public Health Nursing 12, 366-73.

Courtney, R., Ballard, E., Fauver, S., Gariota, M. and Holland, L. 1996: The partnership model: working with individuals, families, and communities toward a new vision of health. Public Health Nursing 13, 177-86.

Davies, B. and Hunt, R. 1994: Classroom competencies and marginal positionings. British Journal of Sociology of Education $15,380-408$.

Department of Health. 1999: Our healthier nation - saving lives. London: The Stationery Office.

Foucault, M. 1975: The birth of the clinic. New York: Vintage Books.

Foucault, M. 1980: Power/knowledge. Gordon, C. editor. Brighton: Harvester Press.

Foucault, M. 1981: The history of sexuality, volume 1. Harmondsworth: Penguin.

Frank, A.W. 2001: Can we research suffering? Qualitative Health Research 11, 353-62.

Gallant, M.H., Beaulieu, M.C. and Carnevale, F.A. 2002: Partnership: an analysis of the concept within the nurse-client relationship. Journal of Advanced Nursing 40, 149-57.

Gilbert, T. 2001: Reflective practice and clinical supervision: meticulous rituals of the confessional. Journal of Advanced Nursing 36, 199-205.

Gillibrand, W. and Flynn M. 2001: Forced externalization of control in people with diabetes: a qualitative exploratory study. Journal of Advanced Nursing 34, 501-10.

Gwyn, R. and Elwyn, G. 1999: When is a shared decision not (quite) a shared decision? Negotiating preferences in a general practice encounter. Social Science and Medicine 49, 437-47.

Hindess, B. 1996: Discourses of power: from Hobbes to Foucault. Oxford: Blackwell.

Kettunen, T., Poskiparta, M., Liimatainen, L., Sjogren, A. and Karhila, P. 2001: Taciturn patients in health counseling at a hospital: passive recipients or active participators? Qualitative Health Research 11, 399-422.

Kingfisher, C.P. and Millard, A.V. 1998: 'Milk makes me sick 
but my body needs it': conflict and contradiction in the establishment of authoritarian knowledge. Medical Anthropology Quarterly 12, 447-66.

Kress, G. 1985: Linguistic processes in socio-cultural practice. Victoria: Deakin University Press.

Laine, C. and Davidoff, F. 1996: Patient-centred medicine: a professional evolution. Journal of the American Medical Association 275, 152-56.

Long, J. 1992: Foucault's clinic. Journal of Medical Humanities 13, 119-38.

Lupton, D. 1997: Consumerism, reflexivity and the medical encounter. Social Science and Medicine 45, 373-81.

Marinker, M. 1997: From compliance to concordance: achieving shared goals in medicine taking. London: Royal Pharmaceutical Society of Great Britain. accessed online through Medicines Partnerships website: http://www.concordance.org (see 'reports' section of website).

Morse, J.M., Mitcham, C., Hupcey, J.E. and Tason, M.C. 1996:
Criteria for concept evaluation. Journal of Advanced Nursing 24, 385-90.

Paterson, B. 2001: Myth of empowerment in chronic illness. Journal of Advanced Nursing 34, 574-81.

Silverman, D. and Bloor, M. 1990: Patient-centered medicine: some sociological observations on its constitution, penetration, and cultural assonance. Advances in Medical Sociology 1, 325.

Smith, D.E. 1999: Writing the social: critique, theory and investigations. Toronto: University of Toronto Press.

Wilson P.M. 2001: A policy analysis of the Expert Patient in the United Kingdom: self-care as an expression of pastoral power? Health and Social Care in the Community 9, $134-42$.

Wooldridge, M. 2000: Self-management the key to living with chronic disease. Retrieved June 22, 2001, from the World Wide Web: http://www.health.gov.au:80hfs/mediarel/yr2000/ mw/mw20069.htm 